\title{
Dialektika Musik Tradisi atas Musik Modern pada Musik Hybrid di Keraton Yogyakarta
}

\author{
M. Hari Sasongko ${ }^{1}$, Supriyadi ${ }^{2}$ \\ ${ }^{1}$ Pascasarjana, Sekolah Tinggi Theologia Abdiel, Ungaran, Jawa Tengah, Indonesia; \\ 2Etnomusikologi, FSP Institut Seni Indonesia Yogyakarta, Bantul, Yogyakarta, Indonesia \\ ${ }^{(*)} \bowtie$ (e-mail) michaelhari.sas@gmail.com¹, Prietno5000@gmail.com²
}

\begin{abstract}
Abstrak
Pemikiran modern bersifat anti-tradisi, akan tetapi di dalam musik Mars Tradisional Keraton Yogyakarta bertemu dan berdialektika dengan musik Barat (yang melahirkan pemikiran modern sejak Renaisans. Melalui metode dialektika ala Hegel yang dikembangkan Arato Gebhardt, pertemuan ini menghasilkan sintesis, yakni lagu hybrid Keraton, baik instrumen maupun tangga nada dimana kedua unsur kebudayaan hadir bersamaan dalam sebuah pertunjukan musik. Dialektika ini pada hakikatnya adalah "rekonsiliasi". Fenomena ini merupakan perjuangan atas "kesetaraan kekuasaan" sebagai strategi kebudayaan dalam menghadapi dominasi penjajah. Dominasi penjajah ini meliputi segala aspek dari ekonomi, politik, sosial, kebudayaan, dan sebagainya, yang membuat bangsa Indonesia (Boemi Poetera) tidak dapat bergerak.
\end{abstract}

Kata kunci: Tradisional, Modern, Dialektika, Hibrida, Kesetaraan.

\begin{abstract}
Modern thought is anti-traditional. However, in the traditional march music of the Yogyakarta palace, western music (which was born by modern thought since the Renainsance) meet and has a dialectics. Through Hegel's dialectical method developed by Arato Gebhardt, this meeting resulted in a synthesis, namely a palace hybrid song. Both instruments and scales of both cultures exist simultaneously in a musicall performance. This dialectics is essentially "reconciliation". This is the struggle for"equality of power" of cultural strategy in the face of colonial domination. Colonial domination covers various aspects of the economy, political, social, cultural, and so on, which make the Indonesian nation (Boemi Poetera) unable to move.
\end{abstract}

Keywords: Traditional, Modern, Dialectics, Hybrid, Equality

This work is licensed under a Creative Commons Attribution-ShareAlike 4.0 International License. Copyright (C) 2021 Hari Sasongko, Supriyadi

\section{Proses Artikel}

Diterima 20-04-2021; Revisi 17-06-2021; Terbit Online 21-06-2021 


\section{Pendahuluan}

(Arnold J Toynbee, 1960, p.17) dalam An Essay on Man mendefinisikan kebudayaan sebagai challenge and response, maka baik musik tradisional mapun pemikiran modern adalah sebuah kebudayaan. Dalam konteks sejarah musik Barat sendiri, challenge and response ini sudah terjadi. (J. Peter Burkholder, 2014), melihat dari aspek estetika, bahwa periodisasi tradisi musik Barat merupakan challenge and response: Periode Renaisans merupakan respons dari Periode Abad Pertengahan, sekaligus menjadi challenge Periode Barok, begitu seterusnya sampai Periode Modern. Ketika Musik Barat bertemu dengan musik tradisional Indonesia, pola challenge and response ini juga terjadi. Suatu bentuk musik merupakan respon dari bentuk-bentuk kebudayaan sebelumnya, namun dalam konteks yang berbeda.

Perbedaan konteks inilah yang membuat kedua kebudayaan berbeda, bahkan sangat berbeda (kalau tidak boleh dikatakan bertolak belakang). Masalahnya adalah kedua kebudayaan yang bertolak belakang ini kini berada di dalam satu ruang dan waktu. Masingmasing berjalan sendiri-sendiri, bahkan ada kesan keduanya saling "mengingkari", bahkan "meniadakan". Kesan yang tampak, bagi seni tradisional (dalam hal ini musik tradisional) pemikiran-pemikiran modern adalah sesuatu yang asing, yang jauh dari hakiki seni tradisional itu sendiri. Sebaliknya, bagi pemikiran modern, seni tradisional adalah "masa lalu", "dunia antah berantah", sebagai fase kedua dalam rangkaian fase peradaban manusia: teologimetafisik-teknologi, seperti yang diungkapkan August Comte, sang pengagum positivisme. Maka yang terjadi adalah saling curiga, atau sekurang-kurangnya memunculkan artikulasi yang negatif di antara kedua belah pihak.

Melalui konsep dialektika penulis akan membahas simbiosis mutualisme di antara kedua kebudayaan tersebut. Oleh karena berada di dalam ruang dan waktu yang sama, maka tidak seyogyanya jika kedua kebudayaan tersebut berjalan sendiri-sendiri, seperti dua dunia yang tidak memiliki hubungan sama sekali. Hubungan semacam ini tentu tidak menguntungkan semua pihak sebab apapun dan bagaimanapun adanya kedua kebudayaan tetap memiliki kelebihan dan kelemahan. Oleh karena itu dibutuhkan rekonsiliasi di antara keduanya melalui proses dialektis. Tulisan ini berada di dalam tataran konsep dan bukan bentuk, sehingga bukan tidak mungkin memunculkan berbagai perdebatan. Namun perdebatan itu tetap diperlukan karena bagaimana pun juga merupakan bagian dari dialog menuju ke arah yang lebih baik. Oleh karena itu, dalam rangka rekonsiliasi ini, dibutuhkan bagi semua pihak untuk sejenak melepaskan 'atribut' masing-masing untuk membuka diri agar dapat melihat persoalan dengan lebih jernih.

Tulisan ini memiliki dua variabel, yaitu musik tradisional dan pemikiran modern. Pemaparan kebudayaan Jawa dalam konteks ini hanya merupakan sampel yang ciri khasnya tentu saja secara umum terdapat di dalam kebudayaan-kebudayaan Timur (Indonesia) lainnya. Oleh karena itu agar hubungan dan problem-problem keduanya dapat dilihat lebih jelas, maka tulisan ini akan menjelaskan variabel-variabel tersebut dan beberapa sub-variabel yang menyertainya. Deskripsi tentang variabel-variabel tersebut setidaknya dapat menjadi acuan mengenai karakter-karakter, konsep-konsep, dan tujuan-tujuan yang terdapat di masing-masing variabel. 


\section{Pembahasan}

\section{Seni Tradisional dan Pemikiran Modern}

"Tradisi" adalah "kebiasaan sosial yang diturunkan dari suatu generasi ke generasi berikutnya melalui proses sosialisasi" (Judistira, 1996, p.186). Tradisi merupakan pedoman tentang nilai-nilai dan moralitas dalam kehidupan masyarakat. Istilah "tradisi" atau tradition (Inggris), atau traditie' (Belanda) dapat disetarakan dengan "adat": gagasan tentang kebiasaan dari suatu komunitas yang mapan. Menurut (Linday, 1989, p.54), "kesenian tradisional" berhubungan dengan kata "daerah" yang artinya dengan ethnic (Inggris), atau suatu komunitas (Achmad, 1981, p.67). Kesenian tradisional hadir dan berkembang berkaitan dengan makna, fungsi, dan kebudayaan yang melatarbelakangi masyarakat pendukungnya (Irianto, 2017, p.81). Konteks kebudayaan sangat lekat dengan jenis musik ini. Musik etnis, berada dalam konteks itu, yang eksistensinya tidak dapat dipisahkan dari tari, wayang, upacara ritual (Senen, 2015, p.9), mapun teater tradisonal, walaupun menurut (Supanggah, 1995, p.33) dapat juga hadir secara mandiri.

Sebagai gambaran, musik tradisional terkait dengan budaya lainnya, seperti: angklung tradisional di Jawa Barat, digunakan sebagai penghormatan kepada Nyai Pohaci (Dewi padi). Gendang Bele merupakan ansambel gamelan dari Lombok yang digunakan untuk mengiringi prosesi upacara perkawinan dan upacara adat lainnya. Gamelan sekaten dari Yogyakarta maupun Surakarta dipakai untuk syiar agama Islam oleh para Wali Songo di dalam menyebarkan agama Islam di tanah Jawa.

Bentuk dan pengolahannya didasarkan atas cita rasa masyarakat pemiliknya. Masyarakat Jawa dalam konteks ini dipakai sebagai contoh yang dalam berbagai prinsip dasar memiliki kesamaan dengan masyarakat Timur lainnya di Indonesia. Adapun cita rasa yang dimaksudkan adalah memiliki nilai atau norma tertentu seperti: nilai filosofi sebagai pandangan hidup, nilai etik dan nilai-nilai lainnya yang mengungkapkan budaya dari lingkungan mereka.

Istilah "modern" punya banyak makna. Socrates disebut "Bapak Filsafat Yunani Modern"; Rene Descartes dijuluki "Bapak Filsafat Modern" juga. Dalam bidang musik, Claude Debussy disebut "komponis musik modern"; Salvador Dali disebut "pelukis beraliran modern," dalam bidang seni lukis, dan sebagainya. Akan tetapi "modern" yang dimaksud di sini adalah kondisi masyarakat yang dibangun sejak Renaisans (Aufklarung) yang ditandai oleh perkembangan teknologi, sejak penemuan kompas, mesiu, dan mesin cetak oleh Guttenberg hingga berkembangnya sosial media hingga saat ini.

Sejak Renaisans, muncullah pemikiran antroposentris: subjek menjadi pusat kesadaran dan manusia, yaitu kepercayaan pada kekuatan akal budi manusia: klaim kebenaran dianggap sah jika dapat dipertanggungjawabkan secara rasional. Yang metafisik dianggap irasional dan kegelapan sebab harus "tunduk dan percaya tanpa harus mengerti", (Suseno, 2000, p.36). Intinya, rasionalisme secara hakiki bersifat anti-tradisional. Pada gilirannya rasionalitas menjadi manusia semata-mata sebagai 'instrumen' dan manusia modern yang dibangun oleh peradaban Renaisans semata-mata berfokus pada pemikiran rasional: 
The philosophy of the Enlightenment, as a new contemplation of the mind, and its focusing on critical thinking was founded in the scientific progress observed during the 17th and 18th centuries, in the appearance of classical science, whose methodology relies on analysis, experiment and the formulation of theories in the language of mathematics (Pavlidis, 2010, p.77).

Cara berpikir rasional yang positivistis oleh Horkheimer disebut "rasio instrumental", oleh Adorno sebagai "pemikiran identitas" dan oleh Marcuse disebut "rasionalisme teknologis" (Hardiman, 1993, p.78). Inilah latar belakang yang membentuk masyarakat modern seperti sekarang ini. Menurut (Poole, 1993, p.46), masyarakat modern ditandai oleh: 1) dunia pasar; 2) kapitalisme; dan 3) pemisahan antara dunia publik (dunia laki-laki) dan dunia privat (dunia perempuan).

\section{Konsep Dialektika}

Konsep dialektika dikembangkan oleh G.W.F. Hegel, filsuf kelahiran Stuttgard, Jerman (1770). Pandangan ini mempengaruhi pemikir teori kritis Mazhab Frankfurt, yaitu: Max Horkheimer, Theodor W. Adorno, dan Herbert Marcuse, sehingga gaya berpikir mereka sering disebut "Hegelianisme Muda". Menurut banyak filsuf, tradisi filsafat Barat sebetulnya sudah selesai pada Hegel. Pandangan Hegel mirip dengan pemikiran Spinoza: "To understand Hegel's notion substance is to understand how he understood Spinoza's theory," (Reck, 1960: 78). Tulisan ini tidak dimaksudkan membedah teori Hegel, melainkan meminjam model dialektika (tesis-sintesis-antitesis). Teori ini telah dipakai di berbagai bidang termasuk di dalam wacana kritik musik (Sasongko, 2019, p.44)

Istilah "dialektika" berasal dari bahasa Yunani dialektikos yang berarti 'pembicaraan', "pidato", atau "perdebatan", dan digunakan sejak filsuf Zeno, Socrates, dan Plato, (Bagus, 1996), juga dipakai para penganut rasionalisme kritis, termasuk filsuf K.R. Popper. Popper tidak jarang memakai triade (triad) dalam mengolah gagasan-gagasan filsafatnya (Popper, 1940, p.156). Konsep dialektika Hegel berpusat pada hubungan antara tesis-antitesis-sintesis. Triaden ini bersifat timbal balik; The tensions and interactions between the three spheres are 'dialectical' as a relationships (Canive, 2019, p.67).

Tesis pertama adalah 'yang ada'. 'Yang ada' harus dirumuskan lepas daripada segala isi yang konkret, tanpa tambahan apa-apa; tidak mengungkapkan isi apa pun, dan tidak dapat dirumuskan bagaimana. Tesis ini melahirkan "antitesis". Sepanjang "yang ada" belum menerima penentuan lebih lanjut, belum dapat dikatakan bagaimana, "yang ada" ini sama dengan "yang tidak ada". Oleh karena tidak dapat dirumuskan bagaimana, "yang ada" itu sekaligus adalah "yang tidak ada" atau "ketiadaan", yaitu segi negatif dari "yang ada". Intinya adalah di dalam proses dialektis melibatkan dua hal yang bertentangan; antara tesis dengan antitesis. Hubungan keduanya menghasilkan suatu sintesis. Pada tahap awal pemikirannya, Hegel menyebut "ada" sebagai tesis, dan "gerak" sebagai antitesis. Sintesisnya adalah "menjadi". Proses dialektis adalah proses yang bergerak terus-menerus. Misalnya, tesis "menjadi" menimbulkan antitesis "yang dijadikan" atau "yang berada", yang kemudian menghasilkan sintesis "yang tidak terbatas". Begitu seterusnya.

Menurut James K. Feibleman, ini adalah skema yang unik. Di satu sisi saling bertentangan, di sisi lain memiliki timbal baik di dalam unsur-unsurnya; bertentangan namun tidak bisa dipisahkan dan saling tergantung satu dengan yang lain, The key to Hegel lies in 
understanding that for him all opposites (contraries, contradictions, positives-and-privitives, affirmations-and-negations) are considered to be correlatitives," karena no opposition, then no motion (Feibleman, 1960, p.122). Satu unsur menjadi unsur penting bagi unsur lainnya agar dapat terjadi proses dialektis. Hegel melihat manusia sebagai proses, dan proses itu dipahami sebagai hasil pekerjaan, dan hasil pekerjaan adalah realitas. Proses itu adalah gerakan yang terus-menerus terjadi. Realitas sebagai proses ini menyejarah dalam kesadaran peningkatan rasionalitas (Suseno, 1993, p.34).

Dalam berbagai bukunya, Hegel lebih suka menggunakan pola dialog: saling menyangkal; saling memajukan. Menurut Hegel pola dual lebih fundamental daripada pola triade semacam itu. Dalam pola dual, setiap "tesis" mengundang "antitesis" dan setiap antitesis dengan sendirinya merupakan "tesis" yang mengudang "antitesis"-nya lagi - yang dilihat dari tesis semula memang merupakan"sintesis" - tetapi sebenarnya adalah antitesis dari antitesis dan tesis baru yang akan disangkal dalam antitesis baru yang sekaligus sintesis dari antitesis pertama (Forster, 1993, p.78).

Konsep Hegel ini dikritik Arato. Menurut Arato, kalau dialektika semata-mata diartikan sebagai tesis-antitesis-sintesis, tujuan kritik menjadi sulit ter(di)capai. Rumusan itu sering mengaburkan proses (berpikir) dialektis yang sesungguhnya, menjadi semata-mata "komproni" yang berarti "perpaduan", atau malah bisa berarti "saling meniadakan". Arato menegaskan, proses dialektis tidak semata-mata mengarah pada sintesis dalam arti perpaduan, melainkan mengarah pada tujuan yang baru sama sekali, yaitu "rekonsiliasi" yang di dalamnya tercakup pengertian "pembaharuan", "penguatan", "perdamaian". Proses dialektis sebenarnya juga, yang disebut Arato, merupakan working reality-- realitas yang sedang bekerja (Arato, 1982, p.231).

Masalahnya, bagaimana memaknai sintesis "rekonsiliasi" dalam konsep dialektika Arato? Arato banyak dipengaruhi tokoh Frankfurt, Jurgen Habermas, yang mengedepankan "rasio komunikasi", yang menggarisbawahi "etika komunikasi" (Poole, 1993, p.77). Maka makna rekonsiliasi adalah "dialog". Maknanya adalah 1) mencari titik-titik penghubung antara tesis dengan sintesis; atau 2) menciptakan titik-titik penghubungan antara tesis dengan antitesis. Maka fungsi dialog di sini adalah sebagai “jembatan" (bridge). Jembatan inilah yang memungkinkan adanya kebaruan, penguatan, dan perdamaian. Makna yang pertama adalah yang paling rasional, sebab memenuhi kekosongan yang bersifat positif, yang yang ada di dalam tesis, mapun antitesis.

\section{Musik Keraton Yogyakarta sebagai Rekonsiliasi}

Keraton Yogyakarta adalah tempat tinggal Sultan Yogyakarta. Kasultanan Yogyakarta dimulai sejak Perjanjian Giyanti (1755). Berdasarkan perjanjian ini, kerajaan Mataram Islam dibagi dua, yakni Kasunanan Surakarta dan Kasultanan Yogyakarta, dan keduanya mencari identitasnya yang khas, seperti model pakaian, berbagai upacara, maupun bentuk ekspresi keseniannya (termasuk musik).

Dalam hal musik, keraton Surakarta memiliki pola garap yang lembut dan rumit, sementara keraton Yogyakarta lebih tegap dan gagah. Dari identitasnya inilah para musisi keraton Yogyakarta memadukan instrumen musik Barat (diatonis) dengan instrumen musik gamelan (pentatonis), sebagai iringan tari, yang terinspirasi dari lagu-lagu mars (militer) yang dimainkan para musisi Barat (Belanda) di keraton Yoyakarta dan berkembang menjadi lagu prajurit keraton dengan menggunakan instrumen Barat (Surtihadi, 2014, p.28). Perpaduan ini bukan hanya dalam aspek instrumen, tetapi juga modus. 
Fenomena hibriditas musik Jawa-Eropa ini sebetulnya sudah berlangsung sejak lama. Dari catatan J. Groneman, seperti dikutip (Sumarsam, 2003, p.96), tentang Korps Musik Prajurit Keraton Yogyakarta, di kerarton tersebut pada akhir Abad 19 terdapat tiga macam ansambel. Mengenai tiga macam ansambel tersebut Groneman menulis sebagai berikut.

(1) Korp musik yang memainkan campuran instrumen Jawa dan Eropa, (2) Korp Musik yang memainkan instrumen musik Eropa saja, dan (3) Korp Musik yang memainkan instrumen Jawa saja. Sebagai contoh, Korp Musik Prajurit memainkan dua drum Eropa dan satu seruling, sedangkan kelompok lain terdiri dari pemain trompet Eropa, drum Eropa dan seruling, dimainkan bersama-sama dengan instumen Jawa yakni gong, dan bendhe: kecer (symbal kecil) dan kendhang ketipung. Groneman juga menyebutkan bahwa semua pemain musik itu adalah prajurit-musikus Jawa (abdi Dalem Prajurit-Musikan) yang memakai seragam militer Eropa abad ke-19.

Menurut (Kunst, 1973, p.293-294), perpaduan elemen musik Eropa-gamelan Jawa tersebut adalah typically hybrid ensembles (tipikal ensambel yang bersifat hybrid atau blasteran).

Iringan musik mars di keraton Yogyakarta sering dipakai untuk mengiringi tiga jenis tarian, yakni tari bedhaya dan tari srimpi (keduanya ditarikan perempuan), dan tari beksan lawung (ditarikan oleh laki-laki). Tari beksan lawung adalah tari perang-perangan. Tari beksan lawung terdiri dari beberapa gendhing (lagu), yaitu suluk (narasi pembuka), gangsaran (semacam introduksi), dan lagu pokok Bima Kurdho. Dalam proses penyajiannya, diawali dengan suluk, kemudian diikuti dengan gendhing gangsaran. Setelah itu masuk ke Bimo Kurdho. Pada saat Bimo Kurdho ini, instrumen saron dimainkan secara unisono dengan instrumen tiup (trombone, trompet, tuba, flute, klarinet), sedangkan snare drum dan symbal sebagai pengatur ritme dimainkan bersamaan dengan rici'an (perangkat) gamelan lainnya. Inilah bentuk musik hybrid (hibrida) pertama di Indonesia.

Perpaduan ini menggambarkan perjuangan keraton sebagai warga pribumi dalam perjuangan mencapai "kesetaraan kekuasaan" (equality of power) ketika berhadapan dengan dominasi penjajah Belanda dalam konteks budaya. Instrumen tradisional dan instrumen Barat yang dimainkan bersama-sama menggambarkan kesetaraan tersebut: tidak ada yang lebih rendah, tidak ada yang lebih tinggi. Konsep ini juga menggambarkan penghilangan kesan adanya pihak penjajah dengan pihak yang dijajah. Dalam bahasa Arato, ini disebut sebagai "rekonsiliasi". Sebuah rekonsiliasi harus dilaksanakan secara sebanding untuk menciptakan sesuatu yang baru yang tidak timpang.

Selain itu, di dalam perpaduan ini sebenarnya terjadi proses dialektis yang dinamis, antara musik tradisional sebagai tesis dan musik Barat sebagai antitesis. Berdasarkan konsep dialektis Arato, keduanya saling mengukuhkan karena terjadi "pembaharuan", "penguatan", dan "perdamaian" karena telah terjadi "dialog". Di dalam proses dialog telah terjadi pencarian titik-titik penghubung antara tesis dengan antitesis; dan selanjutnya menciptakan titik-titik penghubungan antara tesis dengan antitesis tersebut. Gending Bimo Kudho tidak lain adalah sintesis dari dialektika itu, atau dengan kata lain, Gending Bimo Kudho adalah bentuk konkret dari rekonsiliasi antara musik tradisional dan musik Barat yang terjadi di keraton Yogyakarta; Gending Bimo Kudho adalah working reality- realitas yang sedang bekerja. Pun Gending Bimo Kudho dengan sendirinya membangun dirinya sendiri sebagai 
tesis baru yang pada gilirannya akan diikuti oleh antitesis lainnya, dan proses dialektis itu masih berlangsung sampai sekarang. Contoh tarian Beksan Lawung Ageng dapat dilihat pada PekanKebudayaanNasional, di Youtube.

Berikut ini adalah partitur Gending Bimo Kudho yang ditulis di dalam dua modus, yakni pelog nem dan mayor diatonis.

\section{Gending Bimo Kudho}

Modus: Pelog nem

\section{Saron}

1. 1 .

1.5.

1. 1 .

1.5

1.1

1.5

1. 51

1232

1.1

3123

2313

2313

2312

2235

1. 51

1232

1. 1

3123

$2356 \quad 5.32$

1. . 1

3123

2356

5.32

125

5612

1321

2616

5212

3216

$5454 \quad 3262$

Notasi di atas merupakan notasi kepatihan yang biasa digunakan dalam karawitan Jawa. Dalam pathet (tangga nada) pelog nem, notasi 1 (ji), enharmonis dengan nada 3 ( $m i$ ) dalam solmisasi musik Barat. Apabila pathet nem tersebut dinyanyikan maka dapat dinyanyikan:

6 (nem) 5 (mo) 3 (lu) 2 (ro) 1 (ji) yang enharmonis dengan solmisasi notasi Barat yakni:

1 (do) 7 (si) 5 (sol) 4 (fa) 3 (mi).

Gendhing (lagu) Bimo Kurda

Modus: Mayor diatonis

(Instrumen tiup logam)
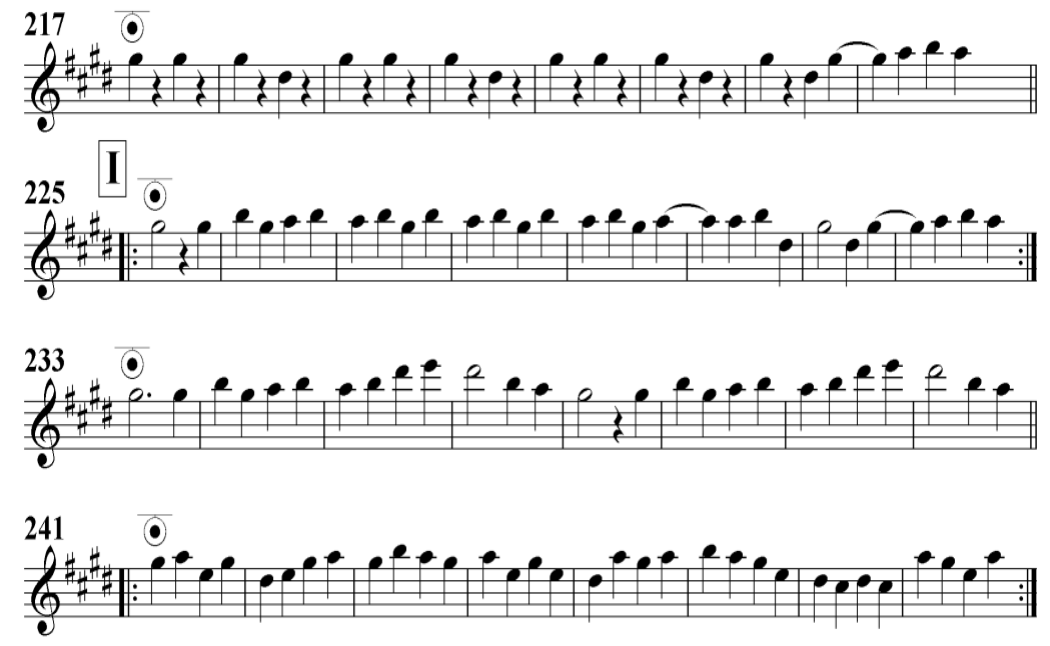

Gambar 1. Notasi ini untuk instrumen tiup yang dimainkan secara unisono 
Lagu Bimo Kurdho merupakan sintesis dari karawitan Jawa sebagai tesis dan brass section sebagai antitesis. Sebagai tesis, karawitan Jawa menggunakan tangga nada pentatonis dengan pathet (modus) nem dan berfungsi sebagai pengiring, walau kadang-kadang instrumen saron dalam karawitan memainkan lagu pokok (balungan) secara unisono dengan brass section. Di sisi lain, brass section adalah antitesis yang menggunakan tanhgga nada diatonis dengan modus E Mayor. Fungsi dari brass section adalah memainkan melodi pokok.

\section{Kesimpulan}

Dialog antara seni tradisional dan pemikiran modern (musik Barat sebagai salah satu produknya) merupakan proses yang tidak pernah berhenti, merupakan working reality. Gendhing bimo kurdha sebagai lagu untuk mengiringi baksan (tari) lawung, merupakan satu dari sekian banyak lagu yang membuktikan adanya fenomena hybrid di khazanah musik Nusantara sejak abad 18. Fenomena ini sekaligus menggambarkan bahwa perjuangan budaya oleh bangsa Indonesia telah dilakukan sejak lama. Perjuangan budaya tersebut berupa perjuangan kesetaraan kekuasaan yang boleh dikatakan "berhasil" tanpa harus menghancurkan yang lain, dengan saling mendukung dan mengukuhkan. Anggapan bahwa semua aspek perjuangan telah kandas di tangan penjajah selama berabad-abad terbukti tidak semuanya benar. Fenomena gendhing bimo kurdha sekurang-kurangnya telah menunjukkan adanya kesadaran akan adanya kesetaraan dengan penjajah. Seniman-seniman keraton Yogyakarta telah membuktikan bahwa mereka memiliki kompetensi estetis yang tidak kalah dengan seniman-seniman produk Renaisans yang telah eksis ratusan tahun sebelumnya. Walaupun konsep tentang "Indonesia" belum terbentuk secara definitif pada saat itu, seniman-seniman keraton Yoyakarta telah menunjukkan kesadaran akan kebangsaan berupa strategi kebudyaan yang tetap terus diperjuangkan hingga saat ini.

\section{Referensi}

Anshory, Nasarudin. (2013). Strategi Kebudayaan: Titik Balik Kebudayaan Nasional, Malang: Universitas Brawijaya Press.

Arato, Andrew, and Eike Gebhardt. (1982). "A Critique of Methodology", in Andrew Arato and Eike Gebhardt(eds.), The Essential Frankfurt School Reader, New York: Continuum.

Bagus, Lorens. (1996). Kamus Filsafat, Jakarta: PT. Gramedia Pustaka Utama.

Burkholder, J. Peter. (2014). A History of Western Music. British: W.W. Norton and Company.

Canive, Patrice. (2019)."The dialectic of recognition:A post-Hegelian approach." EJST (European Journal of Social Theory), Vol. 22.

Daniels, Patricia S., (et al.). (2003). Almanac of World History, Washington DC: National Geographic.

Feibleman, James K. (1960). "Hegel Revisited", Studies in Hegel, Tulane Studies in Philosophy, Volume IX, Tulane University New Orleans..

Forster, Michael. (1993). "Hegel's Dialectical Method", in Derrick C. Beiser(ed.), The Cambridge Companion to Hegel, Cambridge University Press.

Garna, Judistira. (1996). Ilmu-ilmu Sosial: Dasar-Konsep-Posisi, Bandung: Program Pascasarjana Universitas Padjadjaran. 
Hardiman, Budi F. (1993). Menuju Masyarakat Komunikatif: IImu, Masayarkat, Politik dan Postmodernisme menurut Jurgen Habermas, Yogyakarta: Kanisius.

Irianto, Agus Maladi. (2017). "Kesenian TradisionalSebagai Sarana Strategi Kebudayaan di Tengah Determinasi Teknologi Komunikasi Dalam Jurnal Nusa, Vol. 12. No. 1

Junaedi, Deni. (2016). Estetika: Jalinan Subjek, objek dan Nilai, Yogyakarta: Art for Civilization.

Kunst, Jaap. (1973). Music in Jawa: Its History, Its Theory and Its Tecnique. Third Enlarged Edition, (Ed. E.L. Heins. Vol. I. The Hague: Martinus Nijhoff.

Lindsay, Jennifer. (1991). Klasik- Kitsch- Kontemporer: Studi tentang Seni Pertunjukan Jawa, diterjemahkan oleh Nine Bakdi Soemanto, Yogyakarta: Gadjah Mada University Press.

Pavlidis, Periklis. (2020). "Critical Thinking as Dialectics: a Hegelian-Marxist Approach", Journal for Critical Education Policy Studies, Volume 8, Number 2, December 2010

Poole, Rose. (1993). Moralitas dan Modernitas: di Bawah Bayang-bayang Nihilisme, diterjemahkan oleh F. Budi Hardiman, Yogyakarta: Kanisius,

Popper, Karl R., "What is Dialectic?", Mind , Vol. 49,

Reck, Andrew J. (1960). "Substance, Subject, and Dialectic," Studies in Hegel, Tulane Studies in Philosophy, Volume IX, Tulane University New Orleans.

Russel, Bertrand. (1992). Dampak Ilmu Pengetahuan atas Masyarakat, (Terj. Irwanto), Jakarta: Gramedia Pustaka Utama.

Sasongko, M. Hari. (2019). "Makna Kritik Musik: Perspektif Dialektika Hegel”, dalam Sunarto (ed.), Musik dalam Perspektif, Yogyakarta: Thafa Media dan IKA AMISI YK.

Sindhunata. 2019, Dilema Usaha Manusia Rasional. Jakarta: Gramedia.

Subuh. (2016). "Garap Gending Sekaten Keraton Yogyakarta." Dalam Resital: Jurnal Seni Pertunjikan, Vol. 7, No. 3.

Sumarsam. (2003). Gamelan: Interaksi Budaya dan Perkembangan Musikal di Jawa. Yogyakarta: Pustaka Pelajar.

Surtihadi, RM. (2014). "Instrumen Musik Barat dan Gamelan Jawa dalam Iringan Tari Keraton Yogyakarta." Dalam Journal of Urban Society's Art, Vo.1, No.1. 